\title{
Türkiye'de Fisher Hipotezinin Fourier Fonksiyonlarla Analizi
}

\section{Validity of Fisher Hypothesis in Turkey by Using the Fourier Functions}

Pınar Koç a,*

âDr. Öğretim Üyesi, Gümüşhane Üniversitesi, İktisadi ve İdari Bilimler Fakültesi, İktisat Bölümü, 29000, Gümüşhane/Türkiye. ORCID:0000-0002-7843-1228

\begin{tabular}{l} 
MAKALE BİLGİSI \\
Makale Geçmişi: \\
Başvuru tarihi: 01 Ocak 2020 \\
Düzeltme tarihi: 27 Nisan 2020 \\
Kabul tarihi: 02 Mayıs 2020 \\
\hline Anahtar Kelimeler: \\
Eşbütünleşme Analizleri \\
Fisher Hipotezi \\
Fourier Fonksiyonlar \\
Yapısal Kırılmalar \\
Zaman Serileri
\end{tabular}

\section{A RTICLE INFO}

\section{Article history:}

Received 01 January 2020

Received in revised form 27 April 2020

Accepted 02 May 2020

Keywords:
Cointegration Analyzes
Fisher Hypothesis
Fourier Functions
Structural Breaks
Time Series

ÖZ

1985-2017 dönemini kapsayan bu çalışmanın amacı Türkiye'de Fisher hipotezinin geçerliliğini analiz etmektir. Zaman serilerinde yapısal kırılmaların varlığı analiz sonuçlarını önemli ölçüde etkilemektedir. Bununla birlikte yapısal kırılmaların sayısı ve şekli de önemlidir. Bu nedenle bu çalışmada Türkiye'de Fisher hipotezinin geçerliliği Fourier eşbütünleşme testi kullanılarak analiz edilmiştir. Çalışmada faiz oranı ile enflasyon oranı arasında pozitif bir eşbütünleşme ilişkisinin var olduğu tespit edilmiştir. Enflasyon oranındaki \%1'lik artış, faiz oranını \%0.38 artırmaktadır. Bu bağlamda Türkiye'de Fisher hipotezi geçerlidir, ancak faiz oranlarındaki artış, Fisher hipotezinin öngördüğünden daha azdır.

\section{Giriş}

Finansal piyasaların gelişmesi, finansal araç çeşitliliğinin artması ve kısa vadeli sermaye hareketlerinin ülkeler arasında çok hızlı bir şekilde yer değiştirmesi, küresel düzeyde finansal belirsizliklerin artmasına ve hem yerel piyasalarda hem de küresel piyasalarda istikrarın bozulmasına neden olmuştur. 1990'lı yılların başlarında döviz kuru hedeflemesi rejimini uygulayan pek çok ülkede döviz kuru hedeflemesi yerine enflasyon hedeflemesine dayalı para politikaları uygulanmaya başlanmıştır. $\mathrm{Bu}$ bağlamda fiyat istikrarının sağlanması makroekonomik istikrarın temel koşulu olarak kabul edilmiştir. Parasal şokların reel piyasalar üzerindeki etkileri makroekonomik istikrarı sağlamada ve uygun para politikasının belirlenmesinde önemli bir yere sahiptir. Enflasyon oranı ve faiz oranı arasındaki uzun dönemli ilişkilerin analizi para politikalarının geçerliliği konusunda yol gösterici olmaktadir.

Enflasyon oranı ve faiz oranı arasındaki ilişkiler ilk kez Fisher (1930) tarafindan ortaya atılmıştır. Neo Klasik para teorisinin köşe taşlarından biri olan Fisher hipotezi, beklenen

\footnotetext{
*Sorumlu yazar/Corresponding author.

e-posta: pinartorun@gumushane.edu.tr
} 
enflasyon oranındaki artışların reel faiz oranını etkilemeden aynı oranda nominal faiz oranına yansıyacağını ve dolayısıyla paranın yansızlığını ifade etmektedir. $\mathrm{Bu}$ bağlamda Fisher denklemine göre nominal faiz oranı beklenen enflasyon oranı ile reel faiz oranının toplamına eşittir.

Reel faiz oranı, enflasyon beklentilerine değil, sermayenin marjinal verimliliğine ve yatırımcıların zaman tercihlerine göre belirlenmektedir ve uzun dönemde sabittir.

Fisher hipotezi enflasyon hedeflemesi rejiminin de temelini oluşturmaktadır. Enflasyon hedeflemesi rejimini benimseyen ülkelerde gerçekleşen enflasyonun hedeflenen enflasyonun altında kalması durumunda nominal faiz oranı düşürülerek; gerçekleşen enflasyonun hedeflenen enflasyonu aşması durumunda nominal faiz oranı yükseltilerek hedeflenen enflasyona ulaşılmaya çalışılır.

Enflasyon hedeflemesi rejimi Türkiye'de 1990'lı yılların sonlarında tartışılmaya başlanmış olsa da bu rejimin fiilen uygulanmaya başlanması 2000'li yılların başlarında mümkün olabilmiştir. 2002-2005 döneminde Türkiye'de örtük enflasyon hedeflemesi rejimi benimsenirken, enflasyon hedeflemesi için gerekli ön koşulların sağlanmasıyla 2006 yılından sonra açık enflasyon hedeflemesi rejimi uygulanmaya başlanmıştır. Bu bağlamda 1985-2017 dönemini kapsayan bu çalışmada Türkiye'de Fisher etkisinin geçerli olup olmadığı fourier fonksiyonlarla analiz edilmiştir. $\mathrm{Bu}$ çalışmada diğer çalışmalardan farklı olarak, değişkenler arasında eşbütünleşme ilişkisi olduğu tespit edildikten sonra ilişkinin yönünü ve büyüklüğünü tespit edebilmek için fourier denklemlerde yer alan trigonometrik terimler FMOLS ve CCR eşbütünleşme denklemlerine ilave edilerek analiz genişletilmiştir. Dolayısıyla ekonomik krizlerden kaynaklanan yapısal kırılmalarla birlikte uzun dönemli ilişkinin büyüklüğünü ölçme olanağ 1 da elde edilmiştir.

Çalışmada öncelikle teorik altyap1 incelenmiş, 1985-2017 dönemi boyunca enflasyon ve faiz oranlarının izlendiği seyir hakkında bilgi verilmiştir. 3. ve 4. kısımlarda sırasıyla mevcut literatür ve çalışmanın yöntemi ele alınmış, on kısımda tahmin sonuçlarına yer verilerek elde edilen sonuçlar değerlendirilmiştir.

\section{Teorik Çerçeve}

Enflasyon oranı ve nominal faiz oranı arasındaki ilişki ilk kez 1930'larda Irving Fisher tarafından incelenmiş, Fisher (1930) nominal faiz oranlarının reel faiz oranı ile beklenen enflasyon oranının toplamına eşit olduğunu ileri sürmüştür (Cooray, 2002:1). Dolayısıyla Fisher denklemi aşağıdaki gibi yazılabilir;

$$
i_{k t}=\pi_{k t}^{e}+r_{k t}
$$

Denklemde $i_{k t}$, nominal faiz oranlarını temsil ederken, $\pi_{k t}^{e}$ beklenen enflasyon düzeyini ve $r_{k t}$ reel faiz oranını temsil etmektedir.

Fisher hipotezine göre, nominal faiz oranları beklenen enflasyon oranıyla aynı yönde hareket etmekte ve reel faiz oranları sabit kalmaktadır (Barsky, 1987:3). Nominal faiz oranlarının beklenen enflasyon oranındaki değişmelere birebir cevap vermesi beklenmektedir. Çünkü enflasyon oranı tasarruf sahiplerinin getirilerini negatif etkileyecektir.
Enflasyonun yatırım getirileri üzerinde yarattığ nominal faiz oranlarının yükseltilmesi ile telafi edilebilecektir. Fisher etkisi geçerli iken uzun dönemde para politikası araçlarını kullanarak reel faiz oranlarının değiştirilmesi mümkün olmayacaktır.

Mundell (1963) ve Tobin (1965) Fisher denkleminden farklı olarak literatürde Mundell-Tobin etkisi olarak bilinen yeni bir yaklaşımla beklenen enflasyon oranı ve reel faiz oranı arasındaki ilişkiyi incelemiştir. Tobin'e (1965) göre beklenen enflasyon oranındaki artışlar, nominal faiz oranlarındaki artışlardan daha büyük olduğunda reel faiz oranları düşecektir. Ancak, enflasyon bireylerin para talebini ve tüketimini azaltarak tasarrufların artmasına neden olacaktır. Bu bağlamda parasal şoklar reel değişkenler üzerinde de etkili olacaktır. Mundell'e (1963) göre beklenen enflasyon oranındaki artış, bireylerin reel gelir düzeyinde azalmaya neden olacaktır. Enflasyon oranındaki artış elde para tutmanın maliyetini yükselterek para talebini azaltır. Satın alma güçlerini korumak isteyen tüketiciler reel piyasalara yatırım yapacak, artan sermaye birikimi reel faiz oranlarının düşmesine neden olacaktır. $\mathrm{Bu}$ bağlamda enflasyon ekonomik büyümeyi de pozitif etkileyecektir.

Beklenen enflasyon oranındaki artışın faiz oranlarını yükselteceğini ileri süren diğer yaklaşım Friedman (1968) tarafından ileri sürülen likidite etkisi yaklaşımıdır. Bu yaklaşım adaptif beklentiler bağlamında geliştirilmiştir. Geçmiş dönem enflasyon oranı cari dönem beklenen enflasyon oranının temel belirleyicisi iken, enflasyonun temel kaynağı para arzındaki artışlardır. Para arzının artması durumunda para piyasalarında para arz fazlası oluşacaktır. Bu durumda tasarruf sahipleri mevcut para arz fazlasını telafi edebilmek için tahvil satın alımına yöneleceklerdir. Tahvil talebinde meydana gelen bu artış, tahvil fiyatlarını yükseltirken faiz oranlarının düşmesine neden olacaktır. Para arzındaki artışlar, cari dönem enflasyon oranını yükseltirken bir sonraki dönemde enflasyon oranındaki artışa bağlı olarak beklenen enflasyon oranı da yükselecektir. Faizlerin düşmesi ve beklenen enflasyon oranındaki artış, bireylerin finansal olmayan varlıklara yani reel sermaye piyasalarına yatırım yapmalarını sağlayacaktır. Yatırım ve tüketim harcamalarındaki artışa bağlı olarak nominal gelir düzeyi artacak, firmalar artan talebi karşılamak için negatif stok yatırımları yapacak ve üretimlerini artıracaklardır. Kısa dönemde üretimde meydana gelen artış, işçi yanılma modeliyle açıklanmaktadır. İşçi yanılma modelinde emek talebi gerçekleşen reel ücrete bağlı iken emek arzı beklenen reel ücretin bir fonksiyonudur. Firmalar artan talebi karşılamak ve kârlılık düzeyini artırmak için daha fazla emek istihdam etmek isteyecekler ve nominal ücretleri artıracaklardır. Ancak nominal ücretlerde yapılan artış, enflasyonda meydana gelen artıştan daha küçüktür. Ancak işçiler nominal ücretlerinde meydana gelen bu artışı reel ücretlerinde meydana gelen bir artış gibi algılamakta ve emek arzı ve dolayısıyla üretim artmaktadır. Ancak işçiler uzun dönemde aldandıklarını, yani reel ücretlerinin artmadığını, aksine azaldığını fark ederek emek arzını azaltacaklardır. Dolayısıyla uzun dönemde fiili çıktı potansiyel çıktı düzeyine dönecek, ancak fiyatlar genel düzeyi bir önceki döneme göre daha yüksek olacaktır. Üretimde meydana gelen bu azalma, gelir düzeyinde ve finansal varlık talebinde artışa neden olarak faiz oranlarının da tekrar yükselmesine neden olacaktır. Ekonomide 
enflasyonun artacağı beklentisi devam ediyorsa faiz oranları da yükselmeye devam edecektir (Friedman, 1968; 1977).

Miskhin (1981) para arzı artışlarının uzun dönem nominal faiz oranı üzerindeki etkisini etkin piyasalar hipotezi çerçevesinde ele almıştır. Bu yaklaşıma göre para arzındaki artışın uzun dönem faiz oranlarını nasıl etkileyeceği parasal şokların öngörülebilirliğine bağlıdır. Yani para arzında beklenmeyen bir artış olması durumunda uzun dönem faiz oranları, kısa dönem faiz oranlarıyla benzer bir seyir izlemektedir.

Enflasyon oranı ile faiz oranı arasında eşbütünleşme ilişkisinin olması uzun dönemde para politikalarının etkin olmadığı anlamına gelmektedir. Bu bağlamda uygun iktisat politikalarının seçiminde enflasyon oranı ve faiz oranı arasındaki uzun dönemli ilişkilerin analizi önemli rol oynamaktadır.

\subsection{5-2017 Dönemi İtibarıla Türkiye'de Enflasyon ve Faiz Oranlarının Seyri}

Şekil 1'de 1985-2017 döneminde y1llık faiz oranı ve enflasyon oranının izlediği seyir görülmektedir. Şekil incelendiğinde belirli dönemlerde sapmalar gözlense de Türkiye'de enflasyon oranı ve faiz oranlarının aynı yönde seyir izlediği gözlenmektedir.

Şekil 1. Türkiye'de Enflasyon ve Faiz Oranları: 1985-2017 Dönemi

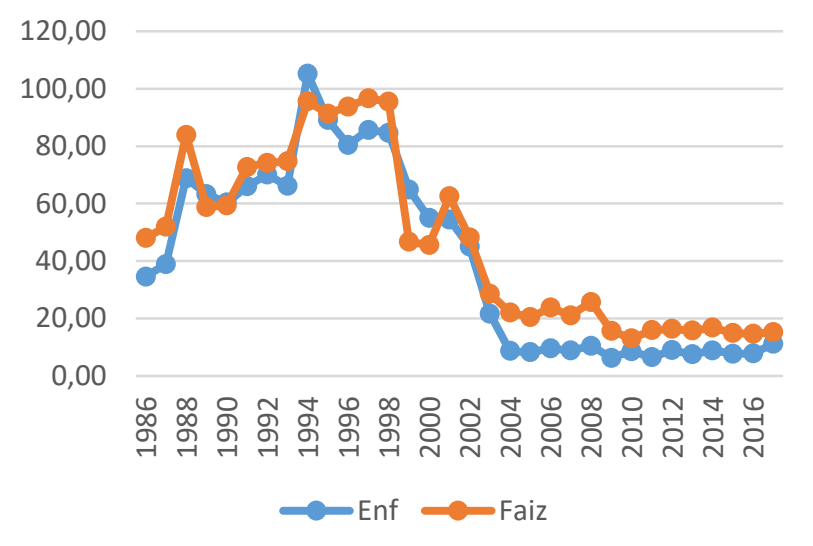

Kaynak: Yazar tarafından oluşturulmuştur.

Enflasyondaki artışla birlikte faiz oranları da yükselme eğilimine girmiştir. Aşağıda ele alınan dönem boyunca enflasyon ve faiz oranlarında meydana gelen değişmeler ve değişmelerin nedenleri incelenmeye çalışılmıştır.

Türkiye ekonomisinde hem uluslararası piyasalara uyum sağlayabilmek hem de yurt içinde makroekonomik istikrarın sağlanabilmesi için çok sayıda düzenleme yapılmıştır. Bu bağlamda 24 Ocak 1980 tarihinde hazırlanan istikrar paketi Türkiye ekonomisi için önemli dönüm noktalarından biridir. $\mathrm{Bu}$ istikrar paketiyle ithal ikameci sanayileşme modeli yerine ihracata dayalı büyüme modeli uygulanmaya başlamıştır.

Yıllar itibarıyla farklılık gösterse de 1981-1987 dönemi TL'nin dolar karşısında sürekli değer kaybettiği bir dönemdir. 1980'li yıllarda yapılan devalüasyonlar ihracatı artırırken faiz oranlarını yükselterek kamu harcamalarının ve dolayısıyla bütçe açıklarının önemli ölçüde artmasına neden olmuştur. Kamu açıklarının karşılıksız para basımı ile finanse edilmesi ve KIT ürünlerine yapılan zamlar enflasyonun artmasina neden olurken (TÜSİAD, 1986: 12-
14), petrol fiyatlarında meydana gelen düşme ve ücretlerin düşürülmesi nedeniyle toplam talepte meydana gelen azalma (Akgül, 2010:147), 1981-1987 döneminde enflasyon oranının 1980 yılına oranla daha düşük olmasında önemli rol oynamıştır. 1981 yılında enflasyon oranı \% 28 iken 1982'de $\%$ 31, 1983'de \% 48 düzeyindedir.

1987-1993 döneminde enflasyon oranı \% 65-\%70 civarında seyretmiştir. 1986 yılından itibaren kamu açıklarının ağırlıklı olarak iç borçlanma ile finanse edilmesi, para piyasalarının kurulması ve 1989 yılının Ağustos ayında sermaye girişlerinin serbestleştirilmesiyle Türkiye ekonomisinde mali piyasaların etkinliği artmıştır. Ancak yüksek kamu açıklarının hakim olduğu bir ekonomide serbest sermaye hareketleri kur ve faiz oynaklığı ile enflasyon oranını yükseltmiştir (Yükseler, 2004:2). Nitekim 1990-1993 döneminde enflasyon oranı \% 65,6 iken dolardaki ortalama nominal artış \% 51,8 ile sınırlı kalmış, hazine bonosu ortalama bileşik faizi \% 77,5 düzeyine yükselmiştir (Mütevellioğlu ve Sönmez, 2009:45). Faiz kur arbitrajı ile reel getirinin yüksek olması bankaların devlet iç borçlanma senetlerine yatırım yapmasına neden olmuş, banka karlılık oranları yükselmiştir. Bu dönemde bütçe açıkları bir önceki dönemde olduğu gibi karşılıksız para basımı yoluyla değil, iç borçlanma ile finanse edilmeye çalışılmıştır. Bütçe açıklarının iç borçlanma ile finanse edilmesi faiz oranlarını yükselterek kısa vadeli sermaye girişlerini artırırken, TL'nin de değer kazanmasına neden olmuştur. Yüksek faiz-aşırı değerli TL ekseninde uygulanan ekonomi politikaları cari açı $\breve{g}_{1}$ artırarak ülke ekonomisinin 1994 yilında ülkeyi yeni bir krize sürüklemiştir. Krizin etkisiyle enflasyon oranı \%70'lerden \%105'lere yükselmiştir. 5 Nisan istikrar paketi uygulanmaya başlanmasına rağmen, 1995 yılında enflasyon oranı ancak $\% 89$ düzeylerine gerileyebilmiştir.

5 Nisan Kararlarıyla 1995-1998 Nisan döneminde Türkiye ekonomisinde görülen büyüme eğilimi, artan siyasal istikrarsızlıklar, 1997 Güney Doğu Asya ve 1998 Rusya krizleri nedeniyle sona ermiştir. Bu krizler ihracatın azalmasına, dış ticaret açıklarının artmasına ve büyük miktarlarda sıcak para çıkışına neden olarak 1998 krizini tetiklemiştir. 1999 yılı sonlarında ekonomi \%6 oranında küçülmüş, enflasyon \%65'e yükselmiş ve faiz oranları ile bütçe açıkları sıçrama yapmıştır.

Ekonomideki bu bozuk gidişatın düzeltilebilmesi adına IMF ile görüşmeler yapılmaya başlanmış, 1998 yılının Haziran ayında IMF ile yakın izleme anlaşması imzalanmıştır. IMF ile yapılan görüşmelerin arkasından koalisyon hükümetinin kurulması ekonominin iyiye gideceği yönündeki umutları artırırken, 17 Ağustos depreminin de neden olduğu mali yük IMF ile bir standby anlaşması imzalamayı kaçınılmaz hale getirmiş, 09.12.1999 tarihinde üç yıl süreli bir standby anlaşması imzalanmıştır (Aydoğan, 2004:97). Bu standby anlaşmasıyla dezenflasyonist bir istikrar politikası yürürlüğe konulmuştur. Program döviz kurunun çıpa olarak kullanılmasına dayanmaktadır. Buna göre enflasyon birinci yılın sonunda \%35'e çekilecekti. Bu doğrultuda belirlenen aylık enflasyon değerlerine göre döviz kuru belirlenecek ve kur Temmuz 2001'e kadar dar bir bantta seyredecekti (Ülgen, 2007:302). Böylece enflasyonun döviz sepetindeki yüzde değişime yaklaşması hedeflenerek TÜFE için \%25, $\% 12$ ve $\% 5$ 'lik hedefler konmuştur. Ancak; döviz sepetindeki değişim oranı \%20 iken 2000'de TÜFE \%39, 
TEFE \%32 artmıştır. Bu durum programa duyulan güveni sarsmış, 1999'da kamu borçlanmasının ortalama reel faiz oranı \%34 iken 2000 yılının ilk 11 ayında \% 0’a gerileyerek tüketim harcamalarının artmasına ve bankaların tüketici kredilerine yönelmelerine neden olmuştur (Sönmez, 2004:172).

Talep genişlemesinin kur politikası ve serbest dış ticaret rejimiyle beslenmesi sonucunda dış açıklar hızla artmış, cari açığın yükselmesi devalüasyon söylemlerini ve beklentisini gündeme getirmiştir. Bununla birlikte dövizin denetlenip faizin serbest birakılmasiyla (Ülgen, 2007:302) faiz arbitrajından yararlanmak isteyen bankalar yurt dışından kısa vadeli borçlanarak yüksek faizli uzun vadeli kamu borçlanma araçlarına yatırım yapmaya başlamışlardır. Bu durum bankaların açık pozisyonlarını artırarak kur riskinin artmasına neden olmuştur. Sıcak parayı ellerinde tutanlar dış dengenin sürdürülemez olduğunu anladıkları anda sermayelerini çekmişlerdir. Sermaye kaçışının artması döviz talebini artırarak kırılgan bankacılık sistemini derinden sarmış ve Kasım 2000'de ekonomik krizle sonuçlanmıştır (Sönmez, 2004:174).

Kasım 2000'de yaşanan kriz sermaye çıkışlarını hızlandırarak döviz talebini artırmaya devam ederken zamanın Cumhurbaşkanı Ahmet Necdet Sezer'in zamanın Başbakanı Bülent Ecevit'e anayasa kitapçığını firlatması Şubat 2001'de yeni bir ekonomik krizin fitilinin ateşlenmesine neden olmuştur. Yoğun döviz talebi Merkez Bankasının 20-21 Şubat'ta 5 milyar dolarlık döviz satışıyla sonuçlanmış (Kurtoğlu, 2017:658), Interbank piyasasında gecelik faizler \%6000'leri aşarken ortalama gecelik faiz oranları \%4000'lere ulaşmıştır (Kurtoğlu, 2017:302).

Kriz sonrası dönem Türkiye ekonomisi için bir dönüm noktası olmuş, piyasalarda kalıcı dönüşümler yapılabilmesi için çok sayıda düzenleme yapılmış, bu kapsamda 2001 yılının mayıs ayında "Güçlü Ekonomiye Geçiş Programı" uygulanmaya başlanmıştır (TCMB, 2013:16).

$\mathrm{Bu}$ çerçevede kamu kesiminin artan borç yükünün sürdürülebilir bir yapıya kavuşturulabilmesi için sıkı maliye politikası uygulanmış, TCMB'nin kısa vadeli faiz oranları üzerindeki etkisi artırılarak dalgalı kur sistemine geçilmiştir. 11 Eylül saldırılarının iç ve dış piyasalarda yol açtığ istikrarsızlık nedeniyle artan ek finansman ihtiyacı ve 2001 yılında gerçekleşen enflasyonun beklenenin üzerinde olması nedeniyle Güçlü Ekonomiye Geçiş Programı 2002-2004 dönemini kapsayacak şekilde tekrar revize edilerek ekonominin iç ve dış şoklara karşı dayanıklılığının artırılması ve ekonomik kırılganlığın azaltılması (Önder, 2005:234) programın temel amaçları arasına dahil edilmiştir. 2002 yılında makroekonomik hedeflerle uyumlu bir parasal genişlemenin ötesine geçilmeyeceği konusunda ekonomik karar birimlerini ikna edebilmek amaciyla parasal hedefleme politikası uygulanarak parasal hedeflemeye ek olarak fiyat istikrarı hedefi doğrultusunda örtük enflasyon hedeflemesi politikası izleneceği ve beklenen enflasyon değerleri dikkate alınarak kısa vadeli faiz oranlarında değişikliğe gidilebileceği belirtilmiştir (Yiğit, 2009: 46-47).

İç borçların sürdürülebilirliğinden şüphe duyulması, geçmiş enflasyona dayalı fiyatlama alışkanlığı, döviz kuru artış hızı ile enflasyon arasındaki ilişkinin çok kuvvetli olması nedeniyle 2001 yılında örtük enflasyon hedeflemesi rejimi uygulanırken faiz dışı fazla hedefine ilişkin olumlu gelişmelerin yaşanması, geçmiş enflasyon yerine gelecek enflasyona dayalı fiyatlama biçiminin ve dalgalı döviz kuru rejiminin benimsenmesiyle programın başarılı olması için gerekli ön koşullar sağlanarak 01.01.2006 tarihinde açık enflasyon hedeflemesi rejimi uygulanmaya başlanmıştır (TCMB, 2002:7-11). Programın uygulanmaya başlandığı ilk 12 aylık dönemde alınan mali önlemlerle faiz dışı fazla artırılmış, iç talep daralmış, GSMH \% 09,5 oranında gerilemiş ve cari işlemler dengesi fazla vermiş olmasına rağmen Türk lirasının değer kaybetmesi ve kamu fiyat ayarlamaları nedeniyle (Yükseler, 2004:7) gerçekleşen enflasyon hedeflenen enflasyonun üzerindedir ve enflasyon oranı yükselmiştir. 2001 yılında gerçekleşen TÜFE \%68,5'dir.

2002 yılında 11 Eylül saldırıları nedeniyle piyasalarda gerginlik artmış olsa da güçlü ekonomiye geçiş programının 2002-2004 dönemini kapsayacak şekilde revize edilmesi ve IMF tarafından 16 milyar dolarlık ek finansman ve ülke ekonomisinde uygulanan sıkı para ve maliye politikaları enflasyonun önemli ölçüde düşmesini sağlamıştır (Yükseler, 2004:6-7). TCMB (2011) verilerine göre 2002-2005 dönemi boyunca gerçekleşen enflasyon hedeflenen enflasyonun altında kalmıştır. 2002 yılında hedeflenen TÜFE \%35,0 iken gerçekleşen TÜFE \%29,7; 2003 yılında hedeflenen TÜFE $\% 20,0$ iken gerçekleşen TÜFE \%18,4; 2004 yılında hedeflenen TÜFE \%12,0 iken gerçekleşen TÜFE \%9,3; 2005 yılında hedeflenen TÜFE \%8,0 iken gerçekleşen TÜFE $\% 7,7$ 'dir.

Siyasi iktidarın değişmesi ve Irak savaşına rağmen enflasyondaki düşüş eğiliminin devam etmesi Irak savaşının kısa sürede sonuçlanması, uluslararası piyasalardaki olumlu gelişmeler ve dünya genelinde enflasyon oranının düşme eğilimine girmesi, hükümetin yeni ekonomi programını uygulamadaki kararlılı̆̆ ile sık1 para ve maliye politikalarının uygulanmaya devam etmesiyle (Yükseler, 2004:7) açıklanabilir. İlave olarak FED tarafindan uygulanan genişletici para politikaları risk algısını azaltarak TL'nin değer kazanmasını ve faiz oranlarının düşmesini de sağlamıştır. Ancak 2006-2017 dönemi boyunca 2009-2010 yılları dışında beklenen enflasyon oranları hedeflenen enflasyon oranlarının üzerinde kalmıştır. 2006, 2007 ve 2008 yıllarında hedeflenen enflasyon oranları sirasıyla $\% 5, \% 4$ ve $\% 4$ iken gerçekleşen enflasyon oranları sırasıyla $\% 9,7, \% 8,4$ ve \%10,1'dir. Enflasyon hedeflemesine geçilen 2006 yılının ilk aylarından itibaren Türkiye ekonomisi uluslararası konjonktürden kaynaklanan bir dizi şokla karşı karşıya kalmış, bu durum 2006-2008 döneminde gerçekleşen enflasyon oranının hedeflenen enflasyon oranından sapmasında etkili olmuştur. 2006 Mayıs-Haziran döneminde küresel piyasalarda risk algısının değişmesi nedeniyle gelişmekte olan ülkelerde yaşanan sermaye çıkışları kuraklığın yarattığ 1 arz çokları nedeniyle gida ve enerji fiyatlarında meydana gelen artış (TCMB, 2013:19) enflasyonun yükselmesinde rol oynayan temel faktörlerdir.

2009-2010 döneminde küresel kriz de göz önünde bulundurularak gelecek dönem enflasyon oranının artacağı öngörüsünde de bulunularak hedeflenen enflasyon oranı yükseltilmiştir. 2009-2010 döneminde hedeflenen enflasyon oranları sırasıyla $\% 7,5$ ve $\% 6,5$ iken, gerçekleşen enflasyon oranları sırasiyla \%6,5 ve \%6,4'dür. Enflasyon beklentileri artarken ele alınan dönemde gerçekleşen enflasyon hedeflenen enflasyonun üzerinde olmakla birlikte bir önceki döneme göre enflasyon oranı düşmüştür. Söz konusu yıllarda 
küresel krizin finansal piyasalarda etkisini göstermesi sonucu sermaye çıkışları yaşanmış, gelişmekte olan ülkelerde yerli para önemli ölçüde değer kaybetmiştir. Finansal belirsizlikten kaynaklanan para talebi artışı küresel düzeyde emtia ve gıda talebini azaltarak enflasyon oranının düşmesine neden olmuştur. TCMB söz konusu dönemde piyasadaki daralmayı önlemek amacıyla 2008 Aralık ayında gecelik faizleri \% 18,75 'den \% 17,50'ye, borçlanma faizlerini ise \%16'dan \%15'e düşürmüştür (Peker, 2011:499).

2011-2017 dönemi hedeflenen ve beklenen enflasyon rakamları incelendiğinde gerçekleşen enflasyonun hedeflenenin üzerinde olduğu görülmektedir. Ele alınan dönemde hedeflenen enflasyon oranı $\% 5$ düzeyinde iken gerçekleşen enflasyon 2017 yılında \%11,92'ye kadar yükselmiştir. TL'nin değer kaybına bağlı olarak temel mal fiyatlarında meydana gelen artış enflasyon üzerinde belirleyici rol oynarken gıda fiyatlarındaki artışlar, enerji fiyatları ve ÖTV oranlarındaki yükseliş ve kur geçişkenliği TCMB (2011; 2012; 2014; 2016; 2017) son dönemde enflasyon oranı üzerinde etkili olan faktörlerdir.

\section{Literatür Taraması}

Literatürde Fisher hipotezinin geçerliliğini sınayan çok sayıda çalışma mevcuttur. Aşağıda özellikle son dönemlerde yapılan çalışmalar incelenmiştir. Payne ve Ewing (1997), Malliorupulos (2000), Granville ve Mallick (2004), Christopoulos ve Leon-Ledesma (2007), Westerlund (2008), Nusair (2008), Ito (2009), Argyro (2010), Lanne (2006), Toyoshima ve Hamori (2011), Ogbonna (2013), Jareno ve Tolentino (2013), Tule vd. (2014), Haug (2014), Yaya (2015), Abbritti vd. (2016), Elibeyli ve Akbulaev (2017), Kim vd. (2018) Caporale ve Gil- Alana (2019) farklı ülkeler ve farklı dönemler için için Fisher etkisinin geçerliliğini inceleyen çalışmalardır. Sadece Westerlund (2008), Elibeyli ve Akbulaev (2017) ve Caporale ve Gil- Alana (2019) tarafından yapılan çalışmalarda Fisher etkisi bulunmadığı sonucuna ulaşılmıştır. Westerlund (2008) tarafından yapılan çalışma 29 OECD ülkesini kapsarken, Ogbanna (2013) Nijerya için, Elibeyli ve Akbulaey (2017) Azerbaycan için Fisher etkisinin geçerliliğini sınamıştır.

Türkiye'de Fisher hipotezinin geçerliliğini farklı dönemler ve farklı metodolojiler kullanarak analiz eden çalışmalar mevcuttur.

Berument ve Jelassi (2002), Çakmak vd. (2002), Turgutlu (2004), Yamak ve Abdioğlu (2007), Gül ve Açıkalın (2008), Y1lanc1 (2009), Bozoklu ve Y1lanc1 (2011), Bayat (2011), İncekara vd. (2011), Mercan (2013), Köksel ve Destek (2015), Tanriöver ve Yamak (2015), Lebe ve Arda Özalp (2016), Küçükaksoy ve Akalın (2016), Tunalı ve Erönal (2016), Güriş vd. (2016), Başar ve Karakuş (2017) ve Çinko (2017), Sağlam (2018), Songur (2019) ve Özer (2019), Kılcı (2019) Fisher hipotezinin geçerliliğini sınayan çalışmalar arasında yer almaktadır. Berument ve Jelassi (2002) Türkiye'nin de içinde olduğu 26 ülkede,Küçükaksoy ve Akalın (2016) OECD ülkelerinde, Bozoklu ve Yılancı (2011) 15 gelişmekte olan ülkede Fisher hipotezinin geçerliliğini analiz ederken; belirtilen çalışmalar dışında yer alan çalışmalar Türkiye'de Fisher hipotezinin geçerliliğini analiz eden çalışmalardır. Ele alınan dönem ve seçilen metodolojiye göre elde edilen sonuçlar farklılık göstermektedir.
Çakmak vd. (2002), Turgutlu (2004), ve Açıkalın ve Gül (2008) tarafindan yapılan çalışmalar sabit döviz kuru rejiminin ve döviz kuru hedeflemesine dayalı para politikası stratejilerinin uygulandığı dönemleri kapsamaktadır. Çakmak vd. (2002) , Açıkalın ve Gül (2008) Türkiye'de zayıf Fisher etkisinin geçerli olduğu sonucuna ulaşırken, Turgutlu (2004) geleneksel ve parçalı koentegrasyon testlerini kullanarak yaptığı analizde iki farklı sonuca ulaşmıştır. Geleneksel eşbütünleşme analizinde Fisher hipotezi reddedilirken, parçalı eşbütünleşme analizinde Fisher hipotezi reddedilememektedir.

Yamak ve Abdioğlu (2007), Yılancı (2009), Bayat (2011), İncekara vd. (2011), Mercan (2013), Köksel ve Destek (2015), Tanrıöver ve Yamak (2015), Lebe ve Arda Özalp (2016), Küçükaksoy ve Akalın (2016), Tunalı ve Erönal (2016), Güriş vd. (2016), Başar ve Karakuş (2017) ve Çinko (2017) enflasyon hedeflemesi rejiminin uygulandığı dönemi de kapsayan çalışmalardır. Yılancı (2009) ve Bayat (2011) tarafından yapılan çalışmalar hariç, çalışmaların tamamında uzun dönemde Fisher hipotezinin geçerli olduğu; zayıf da olsa enflasyon oranı ile faiz oranı arasında uzun dönemli bir ilişki bulunduğu tespit edilmiştir.

Yılancı (2009), Bayat (2011) tarafından yapılan çalışmalarda Fisher hipotezinin geçerli olmadığı sonucuna ulaşılmıştır. $\mathrm{Bu}$ çalışmalarda doğrusal modeller yerine doğrusal olmayan eşbütünleşme testlerinin kullanılması farklı sonuçların elde edilmesine neden olmuş olabilir.

Güriş vd. (2016) tarafından yapılan çalışmada doğrusal olmayan threshold eşbütünleşme testi kullanılmasına ve ele alınan dönem Bayat (2011) tarafından ele alınan dönemle benzer bir dönemi kapsamına rağmen, Güriş (2016) Fisher etkisinin geçerli olduğu sonucuna ulaşırken, Bayat (2011) Türkiye'de Fisher hipotezinin geçerli olmadığı sonucuna ulaşmıştır. Bu farklılık threshold deşbütünlşeme testlerinin rejim değişikliklerini daha iyi yakalamasından kaynaklanıyor olabilir.

Sağlam (2018), Songur (2019), Kılcı (2019) ve Özer (2019) tarafından yapılan çalışmalar Fisher hpotezinin fourier fonksiyonlar kullanılarak analiz edildiği çalışmalardır.

Sağlam (2018) "gelecek 11 ülke" olarak adlandırdığ1 Bangladeş, Pakistan, Filipinler, Nijerya, Vietnam, Misır, İran, Meksika, Endonezya, Güney Kore ve Türkiye'de Fisher hipotezinin geçerliliğini panel fourier birim kök testini kullanarak analiz etmiştir. $\mathrm{Bu}$ çalışma Fisher hipotezinin geçerliliği reel faiz oranlarının durağanlığ sınanarak analiz edilmektedir. Reel faiz oranlarının durağan olması Fisher hipotezinin geçerli olduğu anlamına gelmektedir. Çalışmadan elde edilen sonuçlar Filipinler ve Endonezya dışındaki ülkelerde fisher hipotezinin geçerli olduğunu göstermektedir.

Songur (2019) 2002:1-2018:1 dönemi için Türkiye'de Fisher hipotezinin geçerliliğini sinarken; Özer (2019), 1988-2019 dönemi için Türkiye'de Fisher hipotezinin geçerliliğini sınamıştır. Songur (2019) ele alınan dönem için Fisher hipotezinin geçerli olmadığını sonucuna ulaşırken; Özer (2019) Fisher hipotezinin geçerli olduğu sonucuna ulaşmıştır.

Kılc1 (2019) Fourier Granger nedensellik testini kullanarak 2005-2017 dönemi için enflasyon ve merkez bankası gecelik faiz oranları arasındaki nedensellik ilişkini araştırmıştır. 
Çalışma sonuçları merkez bankası gecelik faiz oranlarından enflasyona tek yönlü nedensellik olduğunu göstermektedir.

\section{Araştırmanın Yöntemi}

1985-2017 dönemini kapsayan bu çalışmada Türkiye'de enflasyon ile faiz oranı arasındaki eşbütünleşme ilişkileri fourier fonksiyonlar kullanılarak analiz edilmiştir. Çalışmada TÜFE ve mevduat faiz oranı kullanılmış̧ır. İlgili istatistikler TÜIK tarafindan yayınlanan istatistik göstergeler raporlarından elde edilmiştir. Fourier eşbütünleşme analizlerinin yapılabilmesi için serilerin I(1) olması gerekmektedir. $\mathrm{Bu}$ bağlamda serilerin durağan olup olmadığını test etmek için Fourier ADF ve Fourier KPSS birim kök testleri kullanılmıştır.

\subsection{Fourier KPSS Birim Kök Testi}

Fourier fonksiyonlarına dayalı birim kök testlerinde yapısal kırılmanın sayısı, biçimi ve anlamlı olup olmadıkları dikkate alınabilmektedir. Becker vd. (2006), Fourier fonksiyonlarını KPSS (1992) birim kök testine uygulayarak diğer birim kök testlerinde yer alan eksiklikleri gidermiştir. İlave olarak ChristopoulosveLeon-Ledesma (2010) Fourier ADF birim kök testlerini geliştirmişlerdir.

Becker vd. (2006) aşağıdaki veri yaratma sürecinden yola çıkmışlardır.

$y_{t}=X_{t}^{\prime} \beta+Z_{t}^{\prime} \gamma+r_{t}+\varepsilon_{t}$

$r_{t}=r_{t-1}+u_{t}$

Burada $\varepsilon_{t}$, hata terimini, $u_{t}, \sigma_{u}^{2}$ varyansla benzer dağılıma sahip, bağımsız hata terimidir.

$y_{t}$ 'nin düzey durağan olup olmadığını test edebilmek için; $X_{t}=[1], y_{t}$ 'nin trend durağan

olup olmadığını test edebilmek için $X_{t}=[1, t]$ ' şeklinde tanımlanmıştır. $Z_{t}=[\sin (2 \pi k t / T), \cos (2 \pi k t / T)]^{\prime}$

trigonometrik terim vektörünü içermektedir.

$y_{t}=a_{0}+\gamma_{1} \sin \left(\frac{2 \pi k t}{T}\right)+\gamma_{2} \cos \left(\frac{2 \pi k t}{T}\right)+e_{t}$

$y_{t}=a_{0}+\beta t+\gamma_{1} \sin \left(\frac{2 \pi k t}{T}\right)+\gamma_{2} \cos \left(\frac{2 \pi k t}{T}\right)+e_{t}$

Düzey durağanlığı sınamak için (3) numaralı denklem, trend durağanlığı sınamak için (4) numaralı denklem tahmin edilerek, bu denklemlere ait hata terimleri elde edilmektedir. Elde edilen hata terimlerine KPSS birim kök testi uygulanmaktadır.

Denklemde yer alan $\mathrm{T}$ gözlem sayısı, $\mathrm{k}$ frekans büyüklüğ̈̈dür. Sonuçlar yorumlanırken uygun frekans büyüklüğü için elde edilen $\tau$ istatistiği ile Becker vd. (2006) tarafından türetilen tablo değerleri karşılaştırılmaktadır. $\mathrm{H}_{0}$ hipotezi serilerin durağan olduğunu söyler. Dolayısıyla Fourier KPSS birim kök testinde serilerin birim kök içerdiğinin söylenebilmesi için $\mathrm{H}_{0}$ hipotezinin reddedilmesi gerekmektedir. Serilerin durağan olduğu tespit edilirse Fourier denkleminden elde edilen sonuçların kullanılabilmesi için $\gamma_{1}=\gamma_{2}=0$ hipotezinin $\mathrm{F}$ test istatistiği ile sinanması ve $\mathrm{H}_{0}$ hipotezinin reddedilmesi gerekmektedir.

Uygun frekans değerleri seçmek için, (3) ve (4) numaralı denklemlerde yer alan $\mathrm{k}$ değerlerine 1 'den 5'e kadar değerler verilmekte ve hata kareler toplamının en küçük değere sahip olduğu model kullanılmaktadır.
FKPSS birim kök testinde test istatistiği;

$\tau_{\mu}(\mathrm{k})$ veya $\tau_{T}(\mathrm{k})=\frac{1}{T^{2}} \frac{\sum_{t=1}^{T} S_{t}(k)^{2}}{\sigma^{2}}$

formülüyle tahmin edilmektedir. Denklemde yer alan $S_{t}$ hata kareler toplamını verirken, $\mathrm{k}$; hata kareler toplamını minimum yapan frekans değerini; $\mathrm{T}$, gözlem sayısını; $\sigma^{2}$ modele ait uzun dönem varyans değerini ifade etmektedir.

\subsection{Fourier ADF Birim Kök Testi}

Christopoluos ve Leon-Ledesma (2010) tarafindan geliştirilen bu modellerde (3) numaralı denklemlerden yola çıkılmakta ve denklemlerden elde edilen kalıntılara ADF birim kök testi uygulanmaktadır.Fourier ADF birim kök testinde serinin birim kök içerdiğini belirten sıfır hipotezinde karşı, serinin birim kök içermediğini belirten alternatif hipotez sinanmaktadır. Sifir hipotezinin reddedilmesi serinin deterministik fonksiyon etrafinda durağan olduğu anlamına gelmektedir.

\subsection{Fourier Eş Bütünleşme Testi}

Tsong vd. (2016) tarafından geliştirilen Fourier eş bütünleşme analizlerinde aşağıdaki regresyon denkleminden yola çıkılmaktadır.

$y_{t}=d_{t}+x_{t}^{\prime} \beta+\eta_{t}, \quad \mathrm{t}=1,2 \ldots \ldots . \mathrm{T}$

den klemde yer alan $d_{t}$ deterministik bileşendir ve

$d_{t}=\sum_{i=0}^{m} \delta_{i} t^{i}+f_{t}$

$f_{t}=a_{k} \sin \left(\frac{2 \pi k t}{T}\right)+\beta_{k} \cos \left(\frac{2 \pi k t}{T}\right)$

şeklinde formüle edilmiştir. Fourier eşbütünleşme testinde test istatistiği;

$C I_{m}^{f}=T^{-2} w_{1}^{-2} \sum_{t=1}^{T} S_{T}^{2}$

formülüyle elde edilmektedir. Formülde yer alan T, gözlem sayısını; $w_{1}^{2}$, eş bütünleşme denklemine ait hata teriminin uzun dönem varyansına ait tahmini değeri; $S_{T}^{2}$; hata kareler toplamın temsil etmektedir.

Modelde $H_{0}$ hipotezi "değişkenler arasında eşbütünleşme ilişkisi vardır" şeklindedir. $H_{0}$ hipotezinin reddi değişkenler arasında eşbütünleşme ilişkisi olmadığı anlamına gelmektedir. Hesaplanan test istatistiğinin kritik değerlerden küçük olması durumunda $H_{0}$ hipotezi reddedilemez. Değişkenler arasında eşbütünleşme vardır.

\subsection{FMOLS Tahmincisi}

Phillip ve Hansen (1990) tarafından geliştirilen FMOLS yönteminde eşbütünleşme denkleminin merkezi limit teoremine uyum sağladığı varsayılarak, otokorelasyon ve içsellik problemleri dikkate alınmaktadır. FMOLS tahmincileri asimptotik olarak sapmasiz, süper tutarlı ve asimptotik olarak normal dağılıma sahip tahmincilerdir. (Phillips ve Hansen, 1990: 120). Denklem sistemi aşağıdaki gibi tanımlanmaktadır;

$y_{t}=\beta^{\prime} x_{t}+u_{1 t}=\theta^{\prime} z_{t}+u_{1 t}$ 


\subsection{CCR Testi}

Park (1992) tarafindan geliştirilen CCR eşbütünleşme denkleminde stokastik şoklar arasındaki uzun dönemli bağımlılı̆̆ yok etmek için değişkenlerin düzey değerleri değil, durağanlaştırılmış değerler kullanılmaktadır.

FMOLS yönteminde olduğu gibi CCR yönteminde de öncelikle hata terimleri $\left(\hat{u}_{t}=\hat{u}_{1 t}, \hat{u}_{2 t}\right)$ ve uzun dönemli kovaryans matrisleri $\Lambda$ ve $\Omega$ elde edilir. FMOLS yönteminden farklı olarak CCR ayrıca eşzamanlı kovaryans matrisinin tutarlı bir $\sum$ tahmincisini gerektirir.

Sonuç olarak KanonikKoentegrasyon Regresyon (CCR) tahmincisi şu şekilde tanımlanır:

$\left[\begin{array}{l}\beta \\ \hat{Y}\end{array}\right]=\left(\sum_{t=1}^{T} Z_{t}^{*} Z_{t}^{* 1}\right)^{-1} \sum_{t=1}^{T} Z_{t}^{*} Y_{t}^{*}$

Burada $Z_{t}^{*}=\left(Z_{t}^{*}, D_{t}^{\prime}\right)$ 'dir. CCR tahmincisi FMOLS'de olduğu gibi süper tutarlı, asimptotik olarak sapmasız ve asimptotik olarak standart normal dağılıma yakınsamaktadır.

\section{Ekonometrik Bulgular}

Eşbütünleşme analizlerinde serilerin I(1) seviyesinde durağan olmaları gerekmektedir. Bu nedenle öncelikli olarak Fourier ADF ve Fourier KPSS testleri kullanılarak serilerin durağan olup olmadıkları test edilmişti

Tablo 1. Fourier Birim Kök Testi Sonuçları

\begin{tabular}{|c|c|c|c|c|c|c|c|}
\hline Düzey & Test & $\mathbf{k}$ & $\tilde{\tau}$ & $\operatorname{Fark}(\Delta)$ & Test & $\mathbf{k}$ & $\tilde{\boldsymbol{\tau}}$ \\
\hline \multirow{2}{*}{ Enflasyon } & FADF & 1 & -0.32 & \multirow{2}{*}{ Enflasyon } & FADF & 1 & -4.59 \\
\hline & FKPSS & 1 & 0.35 & & KPSS & 1 & 0.03 \\
\hline FaizOran & FADF & & -1.76 & \multirow{2}{*}{ FaizOranı } & FADF & 1 & -6.85 \\
\hline Falzuranı & FKPSS & 1 & 0.34 & & FKPSS & 1 & 0.05 \\
\hline \multicolumn{4}{|c|}{ Fourier ADF için F istatistikleri } & $\mathbf{k}$ & \multicolumn{3}{|c|}{$\mathbf{F}$} \\
\hline \multicolumn{4}{|c|}{$\Delta$ Enflasyon } & 1 & \multicolumn{3}{|c|}{116.571} \\
\hline \multicolumn{4}{|l|}{$\Delta$ Faiz } & 1 & \multicolumn{3}{|c|}{17.50} \\
\hline \multicolumn{4}{|c|}{ Fourier KPSS için F İstatistikleri } & $\mathbf{k}$ & \multicolumn{3}{|c|}{$\mathbf{F}$} \\
\hline \multicolumn{4}{|c|}{$\Delta$ Enflasyon } & 1 & \multicolumn{3}{|c|}{17.08} \\
\hline \multicolumn{4}{|l|}{$\Delta$ Faiz } & 1 & \multicolumn{3}{|c|}{15.10} \\
\hline \multicolumn{8}{|c|}{$\begin{array}{l}\text { Not: FADF birim kök testi için kritik değerler sırasılyla \%1, \%5 ve \%10 için }-4,43 \text {, - } \\
3,85 \text { ve }-3,52 \text { 'dir.Christopoluos ve Leon-Ledesma }(2010: 1083) \text { tarafindan elde edilen } \\
\text { kritik değerler kullanılmıştır. FKPSS birim kök testi için kritik değerler sırasıyla \%1, } \\
\% 5 \text { ve } \% 10 \text { anlam düzeylerinde } 0,26,0,17 \text { ve } 0,13 \text { 'tür.Becker vd. (2006 : 389) } \\
\text { tarafindan elde edilen kritik değerler kullanılmıştır. } \\
\text { *FKPSS ve FADF birim kök testinde trigonometrik değerlerin istatistiksel olarak } \\
\text { anlamlılığını sınamak için kullanılan F istatistiği için kritik değerler sırasıyla \%1, \%5 } \\
\text { ve \%10 anlam düzeylerinde } 6.73,4.92 \text {, ve } 4.13 \text { 'tür.Becker vd. (2006:389) tarafindan } \\
\text { elde edilen kritik değerler kullanılmıstır. }\end{array}$} \\
\hline
\end{tabular}

Durağanlığı test etmek için öncelikle k 'ya 1'den 5'e kadar değerler verilerek hata kareler toplamının minimum olduğu model seçilmiş, daha sonra bu modelin kalıntılarına ADF birim kök testi uygulanarak test istatistikleri elde edilmekte ve hesaplanan test istatistikleri kritik değerlerle karşılaştırılarak serilerin durağan olup olmadığına karar verilmektedir. Fourier ADF birim kök testi sonuçları incelendiğinde hesaplanan değerlerin, kritik değerlerden küçük olduğu görülmektedir. Dolayısıyla $\mathrm{H}_{0}$ hipotezi reddedilemez. Seriler düzeyde durağan değildir.

Sonuçların tutarlılığını test edebilmek adına Fourier ADF birim kök testinin yanı sıra Fourier KPSS birim kök testi de yapılmıştır.

Fourier KPSS birim kök testinde $\mathrm{H}_{0}$ hipotezi serilerin durağan olduğunu ifade ederken, $\mathrm{H}_{1}$ hipotezi serilerin durağan olmadığını söylemektedir. Bu bağlamda hesaplanan değerlerin kritik değerlerden büyük olması durumunda $\mathrm{H}_{0}$ hipotezi reddedilir. Seriler durağan değildir. FKPSS tahmin sonuçları incelendiğinde hesaplanan değerlerin kritik değerlerden büyük olduğu görülmektedir. $\mathrm{H}_{0}$ hipotezi reddedilir. Seriler düzeyde durağan değildir.

Serileri durağan hale getirmek için serilerin birinci farkları alınmıştır. Seriler birinci farklarında durağandır. Serilerin durağan olması durumunda elde edilen sonuçların kullanılabilmesi için denklemlerde yer alan trigonometrik değerlere ait katsayıların istatistiksel olarak anlamlı olması gerekir. Trigonometrik değerlerin anlamlılığını sınamak için $\mathrm{F}$ istatistiği kullanılmaktadır. F istatistikleri incelendiğinde trigonometrik değerlere ait katsayıların istatistiksel olarak anlamlı olduğu görülmektedir. Birinci mertebeden durağan seriler arasında eşbütünleşme analizi yapılabilir. Aşağıdaki tablo Fourier eşbütünleşme tahmin sonuçlarını vermektedir.

Tablo 2. Fourier Eşbütünleşme Testi Tahmin Sonuçları

\begin{tabular}{cccccc}
\hline & \multicolumn{5}{c}{ Kritik Değerler } \\
Min SSR & $\mathbf{k}$ & $\mathbf{\tau}$ & $\mathbf{\% 1}$ & $\mathbf{\% 5}$ & $\mathbf{\% 1 0}$ \\
\hline 2.00057 & 2 & 0.163 & 0.200 & 0.276 & 0.473 \\
\hline \multicolumn{2}{c}{ Fourier Eşbütünleşme } & Analizi için F İstatistikleri \\
\hline $\mathbf{k}$ & $\mathbf{F}$ & $\mathbf{\% 1}$ & $\mathbf{\% 5}$ & $\mathbf{\% 1 0}$ \\
\hline 2 & 27.992 & 5.774 & 4.066 & 3.352 \\
\hline
\end{tabular}

Not: Fourier eşbütünleşme testinde eşbütünleşme ilişkisinin varlığını sınamak için kullanılan kritik değerler ve trigonometrik değerlerin anlamlılığını sınamak için kullanılan F istatistiğine ait kritik değerler Tsong vd. (2016: 1190) tarafindan elde edilen kritik değerlerdir.

*SSR hata kareler toplamını temsil etmektedir.

Tsong vd. (2016) tarafindan Fourier fonksiyonlarının kullanılmasıyla literatüre kazandırılmış olan eşbütünleşme testi literatürdeki birçok eşbütünleşme testinin aksine temel hipotez altında eşbütünleşmenin yokluğunu değil varlığını sınamaktadır. $\mathrm{Bu}$ açıdan FKPSS durağanlık testinin eşbütünleşme için genişletilmiş hali olarak düşünülebilecek Fourier eşbütünleşme testi, FKPSS testi gibi yapısal değişimlerin formuna ve sayısına karşın güçlü sonuçlar türetmektedir (Tsong vd. 2016). Hesaplanan değerler tablo değerlerinden küçüktür. $\mathrm{H}_{0}$ hipotezi reddedilemez. Faiz oranları ile enflasyon arasında eşbütünleşme ilişkisi vardır. Eşbütünleşme denkleminde yer alan trigonometrik terimlere ait katsayılar da istatistiksel olarak anlamlıdır.

Fourier eşbütünleşme testinde seriler arasında eşbütünleşme ilişkisinin var olup olmadığı tespit edilebilmekte ancak eşbütünleşme ilişkisinin yönü ve büyüklüğü hakkında bilgi verilmemektedir. $\mathrm{Bu}$ bağlamda Fourier eşbütünleşme denkleminde yer alan minimum frekans değeri dikkate alınarak, FMOLS ve CCR denklemlerine fourier denklemlerde yer alan trigonometrik değişkenler, eklenerek uzun dönem katsayıları hakkında da bilgi sahibi olunmaya çalışılmıştır. Aşağıdaki tabloda FMOLS tahmincisine ait sonuçlar yer almaktadır.

Tablo 3. FMOLS Tahmincisine Ait Sonuçları

\begin{tabular}{|c|c|c|c|c|}
\hline Değgişkenler & Katsayı & $\begin{array}{c}\text { Standart } \\
\text { Hata }\end{array}$ & $t$ istatistiği & $\mathbf{p}$ \\
\hline Enflasyon & 0.377 & 0.069 & 5.398 & 0.0000 \\
\hline $\operatorname{Sin}(2 \pi k t / T)$ & 0.711 & 0.362 & 1.963 & 0.0092 \\
\hline $\begin{array}{c}\operatorname{Cos}(2 \pi k t / \\
T)\end{array}$ & -0.196 & 0.035 & -5.903 & 0.0000 \\
\hline c & 3.755 & 0.015 & 24.270 & 0.0000 \\
\hline $\begin{array}{r}\mathbf{R}^{2}: 0 \\
\text { Düzeltilmis } \\
\text { Standart } \mathbf{H} \\
\text { Uzun Dönem }\end{array}$ & $\begin{array}{l}0.920 \\
\text { ryans: } 0.052\end{array}$ & \multicolumn{3}{|c|}{$\begin{array}{c}\text { Ortalama Bağımlı Var: } 3.600 \\
\text { S. D. Bağımlı Var: } 0.717 \\
\text { Hata Kareler Toplamı: } 2.468\end{array}$} \\
\hline
\end{tabular}


Tahmin sonuçları incelendiğinde enflasyon oranları ile faiz oranları arasında pozitif ve istatistiksel olarak anlamlı bir ilişki olduğu görülmektedir. Enflasyon oranlarındaki \%1'lik değişme faiz oranlarında \%0.37 artışa neden olmaktadır.

Tablo 4. CCR Tahmincisine Ait Sonuçlar

\begin{tabular}{|c|c|c|c|c|}
\hline Değişkenler & Katsayı & $\begin{array}{c}\text { Standart } \\
\text { Hata }\end{array}$ & $t$ istatistiği & $\mathbf{p}$ \\
\hline Enflasyon & 0.388 & 0.070 & 5.542 & 0.0000 \\
\hline $\operatorname{Sin}(2 \pi k t / T)$ & 0.711 & 0.360 & 1.962 & 0.0018 \\
\hline $\operatorname{Cos}(2 \pi k t / T)$ & -0.194 & 0.031 & -5.901 & 0.0000 \\
\hline c & 3.754 & 0.012 & 23.247 & 0.0000 \\
\hline $\begin{array}{r}\mathbf{R}^{2}: \text { } \\
\text { Düzeltilmi } \\
\text { Standart I } \\
\text { Uzun Dönem } \\
0.052\end{array}$ & $\begin{array}{l}0.904 \\
\text { yans: }\end{array}$ & \multicolumn{3}{|c|}{$\begin{array}{c}\text { Ortalama Bağımlı Var: } 3.559 \\
\text { S. D. Bağımlı Var: } 0.714 \\
\text { Hata Kareler Toplamı: } 2.249\end{array}$} \\
\hline
\end{tabular}

CCR tahmincisine ait sonuçlar incelendiğinde enflasyon değişkeninin pozitif ve anlamlı olduğu görülmektedir. Enflasyon oranlarındaki \% 1'lik artış faiz oranlarında \% 0.38 artışa neden olmaktadır.

Tahmin sonuçları incelendiğinde FMOLS ve CCR tahmin sonuçlarının birbiriyle tutarlı sonuçlar verdiği görülmektedir. Bununla birlikte fourier fonksiyonlarda yer alan trigonometrik terimler de istatistiksel olarak anlamlıdır.

\section{Sonuc}

Türkiye ekonomisi özellikle 1970'li yılların sonlarında yüksek enflasyon sorunlarıyla karşı karşıya kalmış, dış şoklar ve ülke içinde uygulanan yanlış politikalar ve kur geçişkenliğinin de etkisiyle enflasyon kronikleşmiş ve ülke ekonomisinin temel sorunlarından biri haline dönüşmüştür. Uygun para ve maliye politikalarının seçimi kronik enflasyon probleminin çözümünde önemlidir. Bu bağlamda Fisher hipotezi para politikalarının etkinliğinin ölçümünde önemli bir yere sahiptir.

Bu çalışmada da 1985-2017 dönemi için Türkiye'de Fisher hipotezinin geçerliliğini analiz etmek amaçlanmıştır. Analizler fourier fonksiyonlara dayalı olarak yapılmış, diğer çalışmalardan farklı olarak CCR ve FMOLS tahmincilerine trigonometrik terimler eklenerek uzun dönemli ilişkinin büyüklüğü ve yönü de tespit edilmiştir. Çalışmada elde edilen sonuçlar faiz oranı ile enflasyon oranı arasında eşbütünleşme ilişkisi olduğunu göstermektedir. Elde edilen sonuçlara göre enflasyon oranında meydana gelen \%1'lik artış, faiz oranını yaklaşık \%0.38 artırmaktadır. Bu bağlamda faiz oranı ve enflasyon oranı arasında uzun dönemde pozitif yönlü ilişki olduğu doğrulanmıştır. Ancak; enflasyon oranlarında meydana gelen artışların nominal faiz oranlarında meydana getirdiği değişme Fisher hipotezinin öngördüğünden daha azdır. Bu bulgu Türkiye'de Fisher hipotezinin geçerli, ancak; etkinliğinin zayıf olduğunu işaret etmektedir. Türkiye'de enflasyon oranı ve faiz oranları arasındaki pozitif uzun dönemli ilişkinin Fisher hipotezinin öngördüğünden daha düşük olması büyük ölçüde finansman ihtiyacından kaynaklanmaktadır. Dış ticaret açıklarının sıcak para girişleriyle karşılanmaya çalışılması ve sermaye girişlerinin pozitif reel getiriye bağlı olmasıyla açıklanabilir. 2002 yilından sonra enflasyon hedeflemesi rejimine geçilmesi diğer bir etkendir. Enflasyon hedeflemesi rejiminde faiz oranları bir politika aracı olarak kullanılmaktadır. Enflasyon hedeflemesi rejiminde gerçekleşen enflasyonun hedeflenen enflasyonun altında kalması durumunda nominal faiz oranı düşürülerek; gerçekleşen enflasyonun hedeflenen enflasyonu aşması durumunda nominal faiz oranı yükseltilerek hedeflenen enflasyona ulaşılmaya çalışılır. $\mathrm{Bu}$ bağlamda enflasyon hedeflemesi rejimine geçildikten sonra Merkez Bankası'nın para politikası üzerindeki etkinliğinin arttığı söylenebilir. Enflasyon hedeflemesi rejiminde faiz oranları fiyat istikrarı için bir araç olarak kullanılmakla birlikte dalgalı kur rejimine geçilmesi kur riskinin piyasa tarafından belirlenmesine neden olmaktadır. Kur riskinin yüksek olduğu dönemlerde enflasyon da yükselmektedir. Bu bağlamda mali disiplinin sağlanması, siyasi istikrar ve açık pozisyonların azaltılması fiyat istikrarı hedefinin sağlanmasında önemlidir.

\section{Kaynakça}

Abbritti, M., Gil-Alana, L.A., Lovcha, Y., \& Moreno, A. (2016). Term Structure Persistence,. Journal of Financial Econometrics, 14 (2), 331-352.

Akgül, I. (2010). 1908 Genç Türk Devriminden Günümüze Paranın Değeri. İçinde: N. Çoşar ve M. Bildirici (Ed.), Tarihi, Siyasi, Sosyal Gelişmelerin Işı̆̆ında Türkiye Ekonomisi, (s.169-216). Bursa: Ekin Kitabevi.

Argyro, K. (2010). Testing the Fisher Effect in OECD Countries: An Empirical Investigation.(Erişim: 25.04.2020)..https://pdfs.semanticscholar.org/673f/e2e 31ad9b21f2e98a14bf3dc146294420242.pdf

Aydoğan, E. (2004). 1980'den Günümüze Türkiye'de Enflasyon Serüveni. Yönetim ve Ekonomi, 11(1), 91 110.

Barsky, R. (1987). The Fisher Hypothesis and the Forecastibility and Persistence of Inflation.. NBER WorkingPaper Series, Working Paper No. 1927, Cambridge.

Başar, S. \& Karakuş, K. (2017). Fisher Hipotezi: Türkiye İçin Tahmini. Uluslararası Sosyal Araştırmalar, 10(5), 794-803.

Bayat, T. (2011). Türkiye'de Fisher Hipotezi'nin Geçerliliği: Doğrusal Olmayan Eşbütünleşme Yaklaşımı. Erciyes Üniversitesi Iktisadi ve İdari Bilimler Fakültesi Dergisi, Say1: 38, 47-60.

Becker, R., Walter, E. \& Lee, J. (2006). A Stationarity Test in the Presence of an Unknown Number of Smooth Breaks. Journal of Time Series Analysis, 27(3), 381409.

Brument, H., Jelassi, M. M. (2002). The Fisher Hypothesis: A Multi-Country Analysis, Applied Economics, 34(13), 1645-1655.

Bozoklu, Ş. \& Yılancı, V. (2011). Fisher Hipotezi'nin Gelişmekte Olan Ülkelerde Geçerliliğinin Testi. İçinde: M. Koçak \& S. Teker (Ed.), Prof.Dr. Sadık Kırbaş’a Armağan Kitap (s.51-62). İstanbul: Okan Üniversitesi.

Caporale, G. M. \& Gil-Alana, L. (2019). Testing the Fisher Hypothesis in the G-7 Countries Using I(d) Techniques. International Economics. Issue: 159, 140150. 
Christopoulos, D. K. \& Leo'n-Ledesma, M. A. (2007). A Long-Run Non-Linear Approach to the Fisher Effect. Journal of Money, Credit and Banking, Volume 39, Issue 2-3, 543-559.

Christopoulos, D. K. \& Leo'n-Ledesma, M. A. (2010). Smooth Breaks and Non-linear Mean Reversion: PostBrettonWoods Real Exchange Rates. Journal of International Money and Finance, 29, 1076-1093.

Cooray, A. (2002). The Fisher Effect: A Review of the Literature.MacquarieUniversityEconomicsResearchPa pers, Working Paper No. 0206.

Çakmak, E, Aksu, H. \& Başar, S. (2002). Fisher Hipotezi’nin Türkiye Açısından Değerlendirilmesi: 1989-2001. Atatürk Üniversitesi İktisadi ve İdari Bilimler Fakültesi Dergisi, 16(3-4), 31-40.

Çinko, L. (2017). Türkiye'de Fisher Hipotezi'nin Geçerliliğinin Sınanması. Social Sciences Research Journal, 6(1), 53-64.

Elibeyli, I. \& Akbulaev, N. (2017). Validity of Fisher Effect in Azerbaijan: Time Series Analysis 1994-2015. Avrasya İşletme ve Íktisat Dergisi, Sayı:9, 106-118.

Fisher, I. (1930). The Theory of Interest. Newyork: Macmillan.

Friedman, M. (1968). The Role of Monetary Policy. The American Economic Review, 58(1), 1-17.

Friedman, M. (1977). Nobel Lecture: Inflation and Unemployment. Journal of Political Economy, 85(3), 451-472.

Granville, B. \& Mallick, S. (2004). Fisher Hypothesis: UK Evidence Over a Century. Applied Economic Letters, 11(2), 87-90.

Gül, E. \& Açıkalın, S. (2008). An Examination of the Fisher Hypothesis: The Case of Turkey. Applied Economics, 40(24), 3227-3231.

Güriş, S., Güriş, B., \& Ün, T. (2016). Interest Rates, Fisher Effect and Economic Dvelopment in Turkey, 19892011. Revista Galega de Economia, 25-2,95-100.

Haug, A. A. (2014). On Real Interest Rate Persistence: the Role of Breaks. Applied Economics, Volume:46, Issue:10, 1058-1066.

Ito, T. (2009). Fisher Hypothesis in Japan: Analysis of LongTerm Interest Rates under Different Monetary Policy Regimes. The World Economy, Volume 32, Issue 7, 1019-1035.

İncekara, A., Demez, S. \& Ustaoğlu, M. (2011). Validity of Fisher Effect for Turkish Economy: Cointegration Analysis. Procedia-Social and Behavioral Sciences,00, $1-10$.

Jareno, F. \& Tolentino, M. (2013). The Fisher Effect: a Comparative Analysis in Europe. Jökull Journal, Vol.63, No: 12, 201-212.

Kılc1, E. N. (2019). Analysis of the Relationship Between Inflation and Central Bank Interest Rates In Turkey. Fourier Approach. UIID-UJEAS, (22), 135-146.
Kim, D., Lin, S., Hsieh, J. \& Suen, Y. (2018). The Fisher Equation: A Nonlinear Panel Data Approach. Emerging Markets Finance and Trade, Volume 54, Issue:1, 162-180.

Köksel, B., \& Destek, M. A. (2015). Türkiye Ekonomisinde Fisher Hipotezinin Test Edilmesi: 2002-2014 Dönemi Üzerine Bir Ampirik Analiz. Uluslararast Sosyal Araştırmalar Dergisi, 8(41), 1247-1253.

Kurtoğlu, R. (2017). Türkiye Ekonomisi (1838-2010), İstanbul: Destek Yayınları.

Küçükaksoy, İ. \& Akalın, G. (2017). Fisher Hipotezi”nin Panel Veri Analizi ile Test Edilmesi: OECD Ülkeleri Uygulamas1. Hacettepe Üniversitesi Íktisadi ve İdari Bilimler Fakültesi Dergisi, 35(1), 19-40.

Kwiatkowski, D., Peter, C.B. P., Schmidt, P. \& Shin, Y. (1992). Testing The Null Hypothesis of Stationarity Against the Alternative of a Unit Root. Journal of Econometrics, 5, 159-178.

Lanne, M. (2006). Nonlinear Dynamics of Interest Rate and Inflation. Journal of Applied Econometrics, 21, 115768.

Lebe, F. \& Arda Özalp, L. F. (2016). Fisher Hipotezinin Alternatif Faiz Oranları ile Türkiye Ekonomisi Açısından Analizi. Dokuz Eylül Üniversitesi İktisadi ve İdari Bilimler Fakültesi Dergisi, 31(1), 95-122.

Malliaropulos, D. (2000). A Note on Nonstationary, Structural Breaks and the Fisher Effect. Journal of Banking \& Finance, Volume 24, Issue 5, 695-707.

Mercan, M. (2013). Enflasyon ve Nominal Faiz Oranları Arasındaki Uzun Dönem İlişkinin Fisher Hipotezi Çerçevesinde Test Edilmesi: Türkiye Örneği. Atatürk Üniversitesi Iktisadi ve İdari Bilimler Dergisi, 27(4), 368-384.

Miskhin, F. .C. (1981). The Real Interest Rate: An Empirical Investigation, NBER Working Paper Series, No: 622, Cambridge.

Mundell, R. (1963). Inflation and Real Interest. Journal of Political Economy, 71, 280-283.

Mütevellioğlu, N. \& Sönmez, S. (2009). Küresellşme, Kriz ve Türkiye'de Neo Liberal Dönüşüm. İstanbul: İstanbul Bilgi Üniversitesi Yayınları.

Nusair, S. (2008). Testing for the Fisher Hypothesis Under Regime Shifts: An Application to Asian Countries. International Economic Journal, 22(2), 273-284.

Ogbonna, B. C. (2013). Testing for Fisher's hypothesis in Nigeria (1970-2012). Journal of Economics and Sustainable Development, 4(16), 163-170.

Önder, T. (2005). Para Politikası: Araçları, Amaçları ve Türkiye Uygulaması, Ankara: Türkiye Cumhuriyet Merkez Bankası Uzmanlık yeterlik Tezi.

Özer, M. Ö. (2019). Türkiye'de Fisher Yaklaşımının Fourier Yaklaşımı ile İncelenmesi. Ankara Hacl Bayram Üniversitesi İ̈BF Dergisi, 21/3, 856-878.

Park, J. (1992). Canonical Cointegrating Regressions. Econometrica, 60, 119-143. 
Payne, J. E. ve Ewing, B. T. (1997). Evidence from Lesson Developed Countries on the Fisher Hypothesis: a Cointegration Analysis. Applied Economic Letters, Volume 4, Issue 11, 683-687.

Peker, H. S. (2011). Türkiye'de Enflasyon ve Enflasyon Hedeflemesi Uygulamasının Değerlendirilmesi. Sosyal Ekonomik Araştırmalar Dergisi, 11(22), 487506.

Phillips, P. C.B. \& Hansen, B..E. (1990). Statistical Inference in Instrumental Variable Regression With I (1) Processes. Review of Economic Studies. 57, 99-125.

Sağlam, Y. (2019). Fisher Hipotezi'nin Fourier Yaklaşımı ile Testi: Gelecek 11 Ülke Grubu Örneği. Journal of Yaşar University, 13/52, 316-321.

Songur, M. (2019). Fourier Yaklaşımı ile Fisher Hipotezini Yeniden Gözden Geçirmek: Türkiye Örneği. C.Ü. Iktisadi ve Ídari Bilimler Fakültesi Dergisi, Cilt:20, Sayı:2, 1-15.

Sönmez, M. (2004). 100 Göstergede Kurtuluştan Çöküşe Türkiye Ekonomisi, İstanbul: İletişim Yayınları.

Tanrı̈ver, B. \& Yamak, N. (2015). Nominal Faiz Oran1Genel Fiyat Düzeyi İlişkisinin Gibson Paradoksu Çerçevesinde Analizi. Maliye Dergisi, Say1: 168, 186200.

Tobin, J. (1965). Money and Economic Growth. Econometrica, 33, 671-684.

Toyoshima, Y., \& Hamori, S. (2011). Panel cointegration analysis of the Fisher effect: Evidence from the US, the UK, and Japan. Economics Bulletin, 31(3), 2674-2682.

Tsong, C., Lee, C. \& Tsaili-Ju; T. (2016). The Fourier Approximation and Testing for the Null of Cointegration. Empirical Economics, 51(3), 10851113.

Tule, M. K., Okpanachi, U. M. Adamgbe, E. T. \& Smith, S. E. (2014). A test of the fisher effect in Nigeria. CBN Economic and Financial Review (EFR), 52(2), 1-32.

Tunalı, H. \& Erönal, Y. (2016). Enflasyon ve Faiz Oranı İlişkisi: Türkiye'de Fisher Hipotezinin Geçerliliği. Süleyman Demirel Üniversitesi İktisadi ve İdari Bilimler Fakültesi Dergisi, 21(4),1415-1431.

Turgutlu, E. (2004). Fisher Hipotezinin Tutarlılı̆̆ının Testi: Parçalı Durağanlık ve Parçalı Koentegrasyon Analizi. Dokuz Eylül Üniversitesi İktisadi ve İdari Bilimler Fakültesi Dergisi, 19(2), 55-74.

Türkiye Cumhuriyet Merkez Bankası (2002). 2002 Yılında Muhtemel Para ve Kur Politikası ve Muhtemel Gelişmeler, Basın Duyurusu, 4 Mart, Ankara, http://www.tcmb.gov.tr, Erişim Tarihi: 10.10.2018

Türkiye Cumhuriyet Merkez Bankası (2011). Yıllık Faaliyet Raporu, Ankara: TCMB Yayınları.

Türkiye Cumhuriyet Merkez Bankası (2012). Yıllık Faaliyet Raporu, Ankara: TCMB Yayınları.

Türkiye Cumhuriyet Merkez Bankası (2013). Enflasyon ve Fiyat İstikrarı, Ankara: TCMB Yayınları.
Türkiye Cumhuriyet Merkez Bankası (2014). Yıllık Faaliyet Raporu, Ankara: TCMB Yayınları.

Türkiye Cumhuriyet Merkez Bankası (2016). Yıllık Faaliyet Raporu, Ankara: TCMB Yayınları

Türkiye Cumhuriyet Merkez Bankası (2017). Yıllık Faaliyet Raporu, Ankara: TCMB Yayınları.

Türk Sanayicileri ve İș İnsanları Derneği (1986). TÜSİAD Ekonomik Araştırmaları, İstanbul: TÜSİAD Yayınları.

Ülgen, G. (2007). Dış Borçlanmanın Analizi ve Türkiye'de Dış Borç Sorunu. İçinde: A. Ay (Ed.) Türkiye Ekonomisi. (s.235-257) Konya: Çizgi Kitabevi.

Westerlund, J. (2008). Panel Cointegration Tests of the Fisher Effect. Journal of Applied Econometrics, 23, 193-223.

Yamak, R. \& Abdioğlu, Z. (2007). Fisher Hipotezinin Testi: Güçlü ve Zayıf Form. Kahramanmaraş Sütçü İmam Üniversitesi Sosyal Bilimler Dergisi, 4(1-2), 1-9.

Yaya, K. (2015). Testing the Long-Run Fisher Effect in Selected African Countries: Evidence from ARDL Bounds Test. International Journal of Economics and Finance, Vol.7, No. 12, 168-175.

Yılanc1, V. (2009). Fisher Hipotezinin Türkiye İçin Sınanması: Doğrusal Olmayan Eşbütünleşme Analizi. Atatürk Üniversitesi İktisadi ve İdari Bilimler Dergisi, 23(4), 205-213.

Yiğit, N. (2009). Türkiye'de ve Yükselen Ekonomilerde Para Politikası Uygulamaları ve Enflasyon Hedeflemesi, Ankara: Maliye Bakanlığı Mesleki Yeterlilik Tezi.

Yükseler, Z. (2004). Türkiye'de Enflasyonist Süreç ve Etkileyen Faktörlere İlişkin Bir Değerlendirme. (Erişim:02.12.2019)http:file:///C:/Users/p\%C4\%B1nar /Downloads/Turkiyede_Enflasyonist_Surec_ve_Etkile ye 